Article

\title{
Preparation and Characterization of Electrospun Double-layered Nanocomposites Membranes as a Carrier for Centella asiatica (L.)
}

\author{
Cláudia Mouro ${ }^{1} \mathbb{D}$, Raul Fangueiro ${ }^{2} \mathbb{D}$ and Isabel C. Gouveia ${ }^{1, *}$ \\ 1 FibEnTech Research Unit, Faculty of Engineering, University of Beira Interior, 6201-001 Covilhã, Portugal; \\ d1684@ubi.pt \\ 2 Centre for Textile Science and Technology (2C2T), University of Minho, 4710-057 Guimarães, Portugal; \\ rfangueiro@dem.uminho.pt \\ * Correspondence: igouveia@ubi.pt
}

Received: 16 October 2020; Accepted: 9 November 2020; Published: 11 November 2020

\begin{abstract}
A wide range of naturally derived and synthetic biodegradable and biocompatible polymers are today regarded as promising materials for improving skin regeneration. Alongside this, these materials have been explored in conjunction with different types of antimicrobial and bioactive agents, especially natural-derived compounds, to enhance their biological properties. Herein, a double-layered nanocomposite dressing membrane was fabricated with two distinct layers. A bottom layer from Chitosan-Sodium tripolyphosphate (CS-TPP) and Poly(vinyl alcohol) (PVA) containing Centella asiatica (L.) (CA) was electrospun directly over a Polycaprolactone (PCL) layer to improve the biologic performance of the electrospun nanofibers. In turn, the PCL layer was designed to provide mechanical support to the damaged tissue. The results revealed that the produced double-layered nanocomposite membrane closely resembles the mechanical, porosity, and wettability features required for skin tissue engineering. On the other hand, the in vitro drug release profile of the PCL/PVA_CS-TPP containing CA exhibited a controlled release for 10 days. Moreover, the PVA_CS-TPP_CA's bottom layer displayed the highest antibacterial activity against Staphylococcus aureus (S. aureus) $(99.96 \pm 6.04 \%)$ and Pseudomonas aeruginosa (P. aeruginosa) $(99.94 \pm 0.67 \%)$, which is responsible for avoiding bacterial penetration while endowing bioactive properties. Finally, the 3-(4,5-Dimethyl-2-thiazolyl)-2,5-diphenyl-2H-tetrazolium bromide (MTT) assay showed that this nanocomposite membrane was not cytotoxic for normal human dermal fibroblasts (NHDF) cells. Therefore, these findings suggest the potential use of the double-layered PCL/PVA_CS-TPP_CA as an efficient bionanocomposite dressing material.
\end{abstract}

Keywords: polycaprolactone; chitosan; sodium tripolyphosphate; poly(vinyl alcohol); Centella asiatica; double-layered nanocomposite membranes

\section{Introduction}

Wound healing is a dynamic and complex process that requires cellular interactions between a wide variety of cell types [1-3]. These interactions are mediated through a coordinated cascade of biological events synergistically controlled by numerous bioactive molecules, such as growth factors, anti-inflammatory agents, and vitamins. However, the physiology of the healing process may be impaired by several factors [1-3]. Among them, bacterial colonization and subsequent infections remain one of the most serious complications after skin structure is compromised $[1,4,5]$.

Generally, when pathogenic microorganisms contaminate skin wounds, the immune system mobilizes its energy trying to suppress the invasion of these pathogens instead of focusing on the re-establishment of the native skin's structural and functional features [1,4-6]. If infection occurs, 
microorganisms, particularly bacteria, can produce endotoxins that stimulate the expression of pro-inflammatory cytokines and encourage an extended inflammatory response. In this case, wounds exhibit increased levels of metalloproteinases (MMPs), which provide an unsuitable environment for the production of new skin's extracellular matrix (ECM) components, delaying or even interrupting the healing process $[1,5,6]$.

Concerning this, several wound dressings displaying antimicrobial properties have been developed to protect the wound from infection and enhance the healing process. Nonetheless, it is essential to improve their performance to suppress this health problem and reduce the occurrence of life-threatening complications [1,5-7]. For this purpose, different combinations of both synthetic and natural biocompatible and biodegradable polymers have been explored to produce 3D nanofibrous membranes that mimic the architecture of the skin's ECM [1,6-8].

So far, to successfully produce nanofibers as potential wound dressings, several techniques have been used, namely self-assembly, phase separation, drawing, template synthesis, and electrospinning. Electrospinning has been considered as one of the most efficient, versatile, and cost-effective methods to produce nanocomposite dressing materials with the desirable features $[1,7]$.

The unique structural and morphological properties of the electrospun nanofibers, like the high specific area to volume ratio, interconnected pores, and the smaller fiber diameters, closely resemble the structure of collagen fibers found in the normal skin's ECM. Alongside this, their porous structure can support cell adhesion, migration, and proliferation, and regulate the release of both growth factors and signaling molecules, which are required to achieve wound healing [1,7-11]. The electrospun nanofibers can also provide quick hemostasis, enhance exudate absorption, nutrients, and gas permeability, as well as preventing bacterial penetration and colonization. Moreover, electrospinning provides the operational ability for incorporating antimicrobial and/or bioactive agents, which enable the improvement of the biologic behavior of these wound dressing materials [1,7-9].

To accomplish that, several different approaches have been used as an alternative to traditional single-fluid electrospinning [12]. Among them, double-fluid and multiple-fluid electrospinning methods have been extensively studied to produce core-shell nanofibers and provide specific release profiles $[13,14]$. In the coaxial electrospinning system, namely in modified coaxial electrospinning processes, different coaxial spinneret needles have been designed [15]. Furthermore, two needles side-by-side have been applied to produce nanofibers with Janus structures $[14,16,17]$. On the other hand, multiple-fluid systems with distinct spinneret arrangements like traditional and modified triaxial spinnerets and electrospun nanofibers with a common shell and two separate cores have been developed to ensure a sustained release of the incorporated agents [14,18-21]. However, those new methods for manipulating the inner chamber structure are complicated. Thus, traditional single-fluid blending electrospinning is still the mainstream method due to its straightforward operation, easy scale-up, and remarkable power for tailoring the components and compositions of resultant composite nanofibers. Additionally, manipulation of deposition on the collector with different electrospun nanofibers has been studied in recent works and is being further explored to improve the functional performances of the electrospun wound dressing materials containing antimicrobial agents [11,22-24].

Among the different antimicrobial agents incorporated so far in electrospun wound dressings, antibiotics and nanoparticles have been widely explored due to their capability to avoid bacteria penetration and colonization into the wound site $[1,5,7,9]$. Nonetheless, the growing threat of antibiotic resistance and their toxicity have encouraged the use of natural products to avoid bacterial contamination. Regarding that, compounds obtained from natural sources, like medicinal plants, have been regarded as a powerful natural supplement for the management and treatment of wounds $[1,7,9,25,26]$ : mainly crude plant extracts, which are ecologically sustainable mixtures rich in interesting bioactive phytochemicals, such as tannins, alkaloids, carbohydrates and glycosides, terpenoids, steroids, flavonoids, and coumarins with multiple healing benefits $[7,9,26,27]$.

Herein, we produced a novel bionanocomposite dressing membrane with a double-layered structure through electrospinning. Polycaprolactone (PCL), a hydrophobic synthetic polymer, 
was used as the main component of the first layer, due to its biocompatibility, desirable mechanical strength, and ability to act as a protective barrier [10,28-30]. On the other hand, the second layer of Poly(vinyl alcohol) (PVA) and Chitosan-Sodium tripolyphosphate (CS-TPP) containing Centella asiatica (L.) (CA) was designed to be in direct contact with the injured skin and enhance the healing process $[30,31]$.

CA is a member of the Apiaceae family, and it has been widely used for the treatment of dermatoses, skin lesions such as burns, excoriations, hypertrophic scars or eczema, and other skin diseases, like leprosy and psoriasis, as well as in non-dermatologic conditions. CA displays different terpenoids, known as centelloids, including asiaticoside, madecassoside, centelloside, centellose, brahminoside, thankunizide, sceffoleoside, brahmoside, and asiatic, centellic, brahmic, and madecassic acids which are responsible for conferring several therapeutic properties to CA [32-34]. Moreover, the extracts obtained from this medicinal plant are known for their capability to stimulate fibroblast proliferation, collagen synthesis, and angiogenesis [32]. In turn, Chitosan (CS), one of the most abundant natural polysaccharides, is known for its ability to stimulate collagen synthesis, as well as bactericidal and hemostatic properties. Alongside this, CS possesses amine functional groups on its backbone chains, which in acidic aqueous media ensure a high density of positive charges [31,35-37]. Thus, under these conditions, CS can be ionically cross-linked with biodegradable and biocompatible polyanions, as the Sodium tripolyphosphate (TPP), forming polyelectrolyte complexes as antimicrobial and/or bioactive agents delivery carriers [31,35]. Nevertheless, the CS-TPP solutions are difficult and unstable to electrospun into a fibrous structure, due to the high viscosity of the CS at low $\mathrm{pH}$ values [31,37-39]. To overcome this limitation, PVA, one of the most commonly used water-soluble synthetic polymers, was added to the CS-TPP blend to enhance fiber-forming ability [31,36,38,39].

Hence, in this work, we aimed to take advantage of the capability offered by double-layered PCL/PVA_CS-TPP_CA to improve the wound healing process, namely the benefits that the ionically cross-linked electrospun PVA_CS-TPP nanofibers display to control the release of the crude CA extract according to the demands for antimicrobial wound care products.

\section{Materials and Methods}

\subsection{Materials}

Centella asiatica (CA) was supplied from a Portuguese botanic shop (CHÁ HUNOS, Lda., Portugal) without any additives. Normal human dermal fibroblasts (NHDF) cells were purchased from ATCC-American Type Culture Collection. Polycaprolactone (PCL) (MW 80.000 g/mol), Chitosan (CS) (low molecular weight) were acquired from Sigma-Aldrich. Polyvinyl Alcohol (PVA) (MW 115.000 g/mol) was purchased from VWR Chemicals. Ethanol absolute, Chloroform, Dimethylformamide (DMF), and Glacial acetic acid were purchased from Fisher Chemical. Nutrient agar (NA), Nutrient broth (NB), and Agar for microbiology were provided from Fluka. Brain Heart Infusion (BHI) broth was obtained from Panreac. Mueller Hinton broth (MHB), Tween 80 , Sodium Hydroxide $(\mathrm{NaOH})$, Sodium Chloride $(\mathrm{NaCl})$, Trypsin, and 3-(4,5-Dimethyl-2-thiazolyl)-2,5-diphenyl-2H-tetrazolium bromide (MTT) were bought from Sigma-Aldrich. Phosphate-buffered saline (PBS) and Sodium tripolyphosphate (TPP) were purchased from Alfa Aesar. All solvents were used as received from the manufacturer.

\subsection{Ethanol Extraction of Crude Centella Asiatica (CA) Plant}

The dried and powdered aerial plant parts (4 g) were macerated using $40 \mathrm{~mL}$ of $95 \%$ ethanol as solvent at room temperature for $24 \mathrm{~h}$. Then, the supernatant from the ethanol extraction was directly filtered through Whatman filter paper, and after that, the acquired filtrate was dried under reduced pressure to obtain dry CA extract. The yield of the fresh plant was $18.81 \%$ (dry weight of the extract obtained after solvent removal per weight of plant) $(w / w)$. Finally, the crude CA extract was stored following good storage practices and next re-suspended in $45 \%(v / v)$ ethanol for further experiments. 


\subsection{Minimum Inhibitory Concentration (MIC) of the Crude CA extract}

Minimum inhibitory concentration (MIC) of the crude CA extract was assessed against Staphylococcus aureus (ATTC 6538) (S. aureus) and Pseudomonas aeruginosa (PA25) (P. aeruginosa) using the broth microdilution method on 96 multi-well polystyrene plates (Sigma-Aldrich), according to the CLSI M07-A6 document. Briefly, serial dilutions of crude CA extract were prepared in sterile Mueller Hinton Broth (MHB) to obtain the desired extract concentrations (between 50 and $0.15 \mathrm{mg} / \mathrm{mL}$ ). Then, $50 \mu \mathrm{L}$ of each CA dilution containing $50 \mu \mathrm{L}$ of a bacterial suspension (adjusted to $\sim 10^{7} \mathrm{CFU} / \mathrm{mL}$ in $\mathrm{MHB}$ ) was applied to the microplate wells in triplicate. The plates were after that incubated at $37^{\circ} \mathrm{C}$ for $18-24 \mathrm{~h}$. The MIC was defined as the lowest concentration of the crude CA extract at which there was no visible growth of $S$. aureus and P. aeruginosa (no solution turbidity on naked eyes). MHB with bacterial suspensions was added as a positive control, whereas only MHB was used as a negative control.

\subsection{Fabrication of the Double-Layered Nanocomposites Membranes}

The double-layered nanocomposites membranes were fabricated using the Nanospider technology (Nanospider laboratory machine NS LAB 500 S from Elmarco S.R.O., Czech Republic, http://www. elmarco.com), as a modified electrospinning method.

Top layer: Initially, a PCL solution (8\% PCL $(w / v))$ was prepared in chloroform/DMF at 30:20 volume ratio. The resultant solution was electrospun at $75.0 \mathrm{kV}$, using a working distance of $15 \mathrm{~cm}$ and an electrode rotation rate of $55 \mathrm{~Hz}$ (electrode spin $=8.8 \mathrm{r} / \mathrm{min}$ ).

Bottom layer: CS-TPP blend was prepared according to a previously reported method by Nguyen et al. [40] using sodium tripolyphosphate (TPP) as a crosslinking agent. Briefly, $0.2 \%(w / v)$ chitosan was dissolved in $0.35 \%$ acetic acid and kept overnight at room temperature. The $\mathrm{pH}$ of the resulting chitosan solution was then adjusted to $\mathrm{pH} 5.5$ using a $0.5 \mathrm{M}$ sodium hydroxide $(\mathrm{NaOH})$ solution. In turn, a TPP solution was prepared in distilled water at a concentration of $0.25 \%(w / v)$. The CS-TPP was produced by dropping the TPP solution into the CS solution under vigorous stirring in a volume ratio of $6: 1$ for $60 \mathrm{~min}$ at room temperature. Afterward, the CS-TPP was blended with 10\% $(w / v)$ of Polyvinyl Alcohol (PVA) dissolved in distilled water at $90{ }^{\circ} \mathrm{C}$ with a volume ratio of 70:30, respectively. Additionally, the crude CA extract incorporation into CS-TPP was achieved by adding $3 \mathrm{mg} / \mathrm{mL}$ of the CA extract in the TPP solution. The CS-TPP_CA was produced following the same procedure as for the CS-TPP.

After polymer solutions were obtained, they were placed in a container with a rotating spinning electrode, and electrospun on top of the recently prepared PCL's top layer at an electrode spin of $45 \mathrm{~Hz}$ (electrode spin $=7.2 \mathrm{r} / \mathrm{min}$ ), using a working distance of $15 \mathrm{~cm}$ and an applied voltage of $75 \mathrm{kV}$.

Finally, the fabricated double-layered nanocomposites membranes (PCL/PVA_CS-TPP and PCL/PVA_CS-TPP_CA) were characterized through in vitro assays to assess their appropriateness as a wound dressing material.

\subsection{Characterization of the Produced Double-Layered Nanocomposites Membranes}

\subsubsection{Scanning Electron Microscopy (SEM) Imaging and Analysis}

The surface morphology of the electrospun nanofibers of the top layer (PCL) and bottom layers (PVA_CS-TPP and PVA_CS-TPP_CA) of the developed double-layered nanocomposite membranes was observed using scanning electron microscopy (SEM) (S2700, Hitachi, Tokyo, Japan) at an accelerating voltage of $20 \mathrm{kV}$. First, the samples were mounted on aluminum stubs and sputter-coated with a thin gold layer in an Emitech K550 sputter coater (Quorum Technologies Ltd., Laughton, East Sussex, UK) for better conductivity during imaging. The fiber diameters were measured from the obtained SEM images using ImageJ software (National Institutes of Health, MD, USA) and the size-frequency distributions constructed with GraphPad Prism 6 software (GraphPad Software, La Jolla, CA, USA). 


\subsubsection{Attenuated Total Reflectance-Fourier Transform Infrared Spectroscopy Study}

The chemical composition of the top layer (PCL), the bottom layers (PVA_CS-TPP and PVA_CS-TPP_CA), and their raw materials was analyzed using attenuated total reflectance-Fourier transform infrared spectroscopy (ATR-FTIR, Thermo-Nicolet is10 FT-IR Spectrophotometer, Waltham, MA, USA). The spectra of the samples were recorded in a spectral width ranging from $400-4000 \mathrm{~cm}^{-1}$ with an average of 32 scans $\mathrm{min}^{-1}$ and a spectral resolution of $4 \mathrm{~cm}^{-1}$.

\subsubsection{Differential Scanning Calorimetry (DSC)}

The thermal behavior of the PCL's top layer and the bottom layers of PVA_CS-TPP with and without CA extract was evaluated by differential scanning calorimetry (DSC) (DSC 204 Phoenix Netzsch, Germany). Briefly, about $5 \mathrm{mg}$ of each sample was filled in small aluminum containers, and the non-isothermal scans performed from $30{ }^{\circ} \mathrm{C}$ to $200^{\circ} \mathrm{C}$ at a heating rate of $5{ }^{\circ} \mathrm{C} / \mathrm{min}$, with a nitrogen-replacing atmosphere.

2.5.4. Assessment of the Mechanical Characteristics of the Produced Double-Layered Nanocomposites Membranes

The tensile test was carried out in dry conditions according to the ASTM standard D3039/D3039M to evaluate the mechanical characteristics of the produced double-layered nanocomposites membranes. Briefly, samples of the PCL/PVA_CS-TPP and PCL/PVA_CS-TPP containing CA samples $(n=5)$ were cut into rectangular strips of $1 \mathrm{~cm} \times 4 \mathrm{~cm}$, and then the thickness was measured with a micrometer (Adamel Lhomargy MI20, France). The tensile test was performed using a dynamometer (DY-35 Adamel Lhomargy, France) by using a load cell of $10-\mathrm{N}$. The samples were mounted vertically between the clamps of the tensile tester, and a speed of $2 \mathrm{~mm} / \mathrm{min}$ used until the membranes were ruptured. Finally, the tensile strength, Young's modulus, and elongation at break were determined.

\subsubsection{Measurement of the Total Porosity}

The total porosity of the dried PCL's top layer and bottom layers of PVA_CS-TPP and PVA_CS-TPP_CA was measured using a fluid displacement method and conducted as previously described by Yeh et al. [41]. Absolute ethanol with density $\rho_{\varepsilon}$ was used as displacement liquid because it can easily penetrate the porous structure without inducing negligible shrinking or swelling as a non-solvent of both layers. Briefly, a graduated cylinder with ethanol was weighed $\left(\mathrm{W}_{1}\right)$, then a dried sample with a known weight $\left(\mathrm{W}_{\mathrm{s}}\right)$ was immersed into the cylinder containing the displacement liquid. After that, this assembly was placed in an ultrasonic bath (Ultrasons-H, P-Selecta) for $40 \mathrm{~min}$ at $30^{\circ} \mathrm{C}$. After this period, the volume of ethanol in the graduated cylinder was refilled and weighed as $\mathrm{W}_{2}$. The sample saturated with ethanol was taken out from the cylinder, and its weight determined as $W_{3}$. The porosity $(\varepsilon)$ of both layers was estimated through the following (Equations (1)-(3)):

$$
\begin{gathered}
V_{s}=\frac{\left(W_{1}-W_{2}+W_{s}\right)}{\rho_{\varepsilon}} \\
V_{p}=\frac{\left(W_{2}-W_{3}-W_{s}\right)}{\rho_{\varepsilon}} \\
\varepsilon(\%)=\frac{V_{p}}{\left(V_{p}+V_{s}\right)} \times 100 \Leftrightarrow \varepsilon(\%)=\frac{\left(W_{2}-W_{3}-W_{s}\right)}{\left(W_{1}-W_{3}\right)} \times 100
\end{gathered}
$$

where $V_{s}$ is the volume of the sample, and $V_{p}$ is the volume of the sample pores. For each sample, the porosity measurements were performed in triplicate, and the average \pm standard deviation (S.D.) shown for each sample. 


\subsubsection{Evaluation of Wettability Properties}

The water contact angles (WCA) at the surface of both layers (PCL, PVA_CS-TPP, and PVA_CS-TPP_CA) were determined using a Data Physics Contact Angle Goniometer (OCAH-200) for surface-wetting characterization. Briefly, each sample was placed on the measuring stage, then water drops $(4 \mu \mathrm{L})$ were seated onto the surface of the samples at different locations at $25^{\circ} \mathrm{C}$. The reported WCA values were the average of at least three independent measurements $(n=3)$.

\subsubsection{Analysis of the In Vitro Swelling Behavior}

The swelling degree of the produced double-layered nanocomposites membranes (PCL/PVA_CS-TPP and PCL/PVA_CS-TPP_CA) was investigated in a phosphate buffer solution (PBS) at a $\mathrm{pH}$ of 5.5 by using a gravimetric method. Briefly, the pre-weighted dry samples $\left(\mathrm{W}_{0}\right)$ were immersed in the PBS at $37^{\circ} \mathrm{C}$. At specific time points, the swollen samples were removed from the PBS buffer solution and reweighted after kindly wiping the excess buffer off the samples $\left(\mathrm{W}_{\mathrm{t}}\right)$. All measurements were performed in triplicate $(n=3)$ and the amount of water uptake determined according to the following Equation (4):

$$
\text { Swelling Ratio }(\%)=\frac{\left(\mathrm{W}_{\mathrm{t}}-\mathrm{W}_{0}\right)}{\mathrm{W}_{0}} \times 100
$$

\subsubsection{Study of the In Vitro Biodegradation Profile}

The physical integrity behaviors were analyzed from the weight loss of the produced double-layered nanocomposites membranes. Briefly, the dried samples with the initial weight of $\left(\mathrm{W}_{0}\right)$ were immersed into PBS solution $(\mathrm{pH}=5.5)$ at $37^{\circ} \mathrm{C}$. At predetermined time intervals $(1,4,7$, and 10 days), the samples $(n=3)$ were removed from the PBS solution, rinsed with distilled water to remove residual buffer salts, oven-dried, and reweighted $\left(\mathrm{W}_{\mathrm{d}}\right)$. Finally, the weight loss $(\%)$ of each sample was determined based on Equation (5):

$$
\text { Weight loss }(\%)=\frac{\left(\mathrm{W}_{0}-\mathrm{W}_{\mathrm{d}}\right)}{\mathrm{W}_{\mathrm{d}}} \times 100
$$

\subsubsection{Water Vapor Transmission Rate (WVTR) Analysis}

The gravimetric assay based on the ASTM E96/E96M-15 standard was used to evaluate the water vapor transmission rate (WVTR) of the produced double-layered nanocomposites membranes. Briefly, sample circles (1.2 cm diameter) were cut and carefully attached to the mouths of test tubes containing $10 \mathrm{~mL}$ of deionized water. The circular opening of the test tubes was sealed using parafilm, and the samples-glass tubes assembly placed in an incubator at $37^{\circ} \mathrm{C}$. At predetermined intervals, the amount of water evaporation was estimated by the changes in their weight over time. The WVTR was calculated according to Equation (6):

$$
\text { Water vapor transmission rate }(\mathrm{WVTR})=\frac{\mathrm{W}_{\text {loss }}}{\mathrm{A}}\left(\mathrm{g} / \mathrm{m}^{2} / \text { day }\right)
$$

where $\mathrm{W}_{\text {loss }}$ is the daily weight loss of water and $\mathrm{A}$ is the test area in $\mathrm{m}^{2}$.

\subsection{Analysis of the In Vitro CA Release from Double-Layered Nanocomposites Membranes}

The in vitro release profile of the double-layered nanocomposites membranes containing crude CA extract was investigated in PBS $(\mathrm{pH}=5.5)$ containing $10 \%(v / v)$ of ethanol. The amount of released CA in PBS was monitored by a UV-Vis spectrophotometer at a wavelength of $370 \mathrm{~nm}$ [42]. Briefly, the double-layered PCL/PVA_CS-TPP_CA membranes were kept immersed in PBS buffer at $37^{\circ} \mathrm{C}$ and $100 \mathrm{rpm}$ for 10 days. At specific time points, a fixed volume of released medium was taken out from the incubation medium, and an equal amount of fresh buffer solution refilled to maintain the 
sink condition. The amount of crude CA extract released was measured by converting its detected $\mathrm{UV}$ absorbance to its concentration according to the calibration curve constructed from a series of CA standard solutions (from $0.00 \mathrm{mg} / \mathrm{mL}$ to $5.00 \mathrm{mg} / \mathrm{mL}$ ). After that, the data obtained were evaluated to determine the cumulative percentage of the released CA from the samples at each immersion time point. The experiments were conducted in triplicate $(n=3)$.

\subsection{Assessment of the Antibacterial Properties of the Produced Double-Layered Nanocomposites Membranes}

The antibacterial activity of both layers (PCL, PVA_CS-TPP, and PVA_CS-TPP_CA) was exanimated against $S$. aureus and P. aeruginosa following the guidelines established by the Standard Test Method for Determining the Activity of Incorporated Antimicrobial Agent(s) in Polymeric or Hydrophobic Materials (ASTM E2180-07 standard). Firstly, S. aureus and P. aeruginosa were cultivated in nutrient broth (NB) and brain-heart infusion broth (BHI) in a shaking incubator at $37^{\circ} \mathrm{C}$ and $110 \mathrm{rpm}$ for $18-24 \mathrm{~h}$, respectively. After that, the bacterial suspensions were diluted until the bacterial concentration reached $\sim 10^{8} \mathrm{CFU} / \mathrm{mL}$, then added to the previously prepared agar slurry to facilitate surface interaction. A thin layer of inoculated agar slurry was pipetted onto the samples and then left to gel at room temperature before incubation at $37^{\circ} \mathrm{C}$ for $18-24 \mathrm{~h}$. The surviving bacteria were analyzed immediately $\left(\mathrm{T}_{0 \mathrm{~h}}\right)$ and after incubation $\left(\mathrm{T}_{24 \mathrm{~h}}\right)$ by elution of the agar slurry inoculum from the test samples. After bacteria elution, serial dilutions were made in $\mathrm{NaCl}$ and pipetted on agar plates, and incubated at $37^{\circ} \mathrm{C}$ for 18-24 h. Finally, the number of surviving colonies following incubation was counted, and the counts used to establish the $\log (\mathrm{CFU} / \mathrm{mL})$.

\subsection{Analysis of the In Vitro Cell Viability}

The cytotoxicity of the double-layered nanocomposites membranes (PCL/PVA_CS-TPP and PCL/PVA_CS-TPP_CA) was evaluated through colorimetric 3-(4,5-Dimethyl-2-thiazolyl)-2,5-diphenyl2H-tetrazolium bromide (MTT) assay according to ISO 10993-5 (Biological evaluation of medical devices-Part 5: Tests for in vitro cytotoxicity). Firstly, the normal human dermal fibroblasts (NHDF) cells were cultured in a medium supplemented with fetal bovine serum (FBS) in a humidified incubator at $37{ }^{\circ} \mathrm{C}$ under a $5 \% \mathrm{CO}_{2}$ atmosphere. Afterward, the samples cut into round disks (with a diameter of $\sim 6 \mathrm{~mm}$ ) were placed at the center of each well in 24-well plates, then sterilized by UV irradiation for $1 \mathrm{~h}$ before cell seeding. After that, $1 \times 10^{4}$ cells/well were seeded in each well containing the sterilized membranes and incubated with $5 \% \mathrm{CO}_{2}$ at $37^{\circ} \mathrm{C}$ for 1,3 , and 7 days. During these intervals of time, the medium was removed, and a mixture of fresh culture medium with the MTT reagent added to each well. After being incubated for $4 \mathrm{~h}$ under the same conditions, the content of each well was again removed and replaced by DMSO to dissolve the formazan crystals. Finally, the absorbance of each membrane was measured at $570 \mathrm{~nm}$ using a spectrophotometric plate reader (Biorad xMark microplate spectrophotometer). Cells incubated without samples $\left(\mathrm{K}^{-}\right)$and cells with EtOH $(96 \%)\left(\mathrm{K}^{+}\right)$ were chosen as control groups. The positive control $\left(\mathrm{K}^{+}\right)$was added in separate 24 well plates to avoid false results caused by $\mathrm{EtOH}(96 \%)$.

\subsection{Statistical Analysis}

Statistical analysis was performed from the one-way ANOVA, followed by multiple comparison test Turkey using GraphPad Prism 6 software (GraphPad Software, La Jolla, CA, USA) with a statistical significance of $p<0.05$.

\section{Results and Discussion}

\subsection{Minimal Inhibitory Concentration (MIC) of the Crude CA Extract}

The antimicrobial susceptibility of the crude CA extract was determined by the MIC. The MIC value against $S$. aureus was found to be $1.40 \mathrm{mg} / \mathrm{mL}$, while the value for $P$. aeruginosa was $2.80 \mathrm{mg} / \mathrm{mL}$. These values were lower than those obtained by Yao et al. [43], who revealed MIC values to the 
ethanolic extract of CA of $6.25 \mathrm{mg} / \mathrm{mL}$ and $25 \mathrm{mg} / \mathrm{mL}$ against S. aureus and P. aeruginosa, respectively. These results proved that the antibacterial activity of the medicinal plants depends on the specific active compounds present in the extract.

\subsection{Characterization of the Produced Double-Layered Nanocomposites Membranes}

\subsubsection{Scanning Electron Microscopy (SEM) Imaging and Analysis}

In this study, the surface morphologies and diameter distributions of the electrospun nanofibers from PCL's top layer and the bottom layers of PVA_CS-TPP and PVA_CS-TPP incorporated with the crude CA extract, respectively, are displayed in Figure 1a. The SEM images show that both layers exhibit a random distribution of nanofibers with interconnected pores. The average diameters of the smooth PCL structure were determined to be $277.63 \pm 85.19 \mathrm{~nm}$, which is in agreement with other studies performed with PCL [44]. In turn, the average fiber diameter of the smooth and bead-free structures of PVA_CS-TPP was decreased from $323.85 \pm 91.07 \mathrm{~nm}$ to $284.34 \pm 75.79 \mathrm{~nm}$ when the crude CA extract was incorporated, as a result of reduction of the viscosity of the electrospinning solution. In this way, these results suggest that the produced double-layered nanocomposites membranes resemble the fibrous morphology and architecture of the natural extracellular matrix (ECM) since the nanofibers exhibit diameters within the size range of the collagen fibers of ECM (50-400 nm), being able to promote cell adhesion and proliferation $[45,46]$.
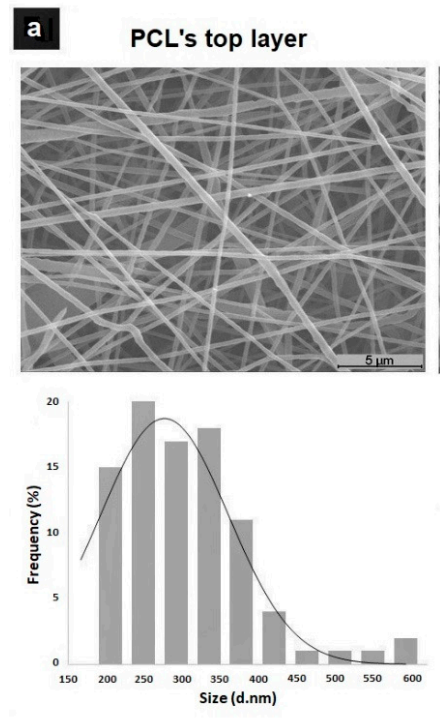

b
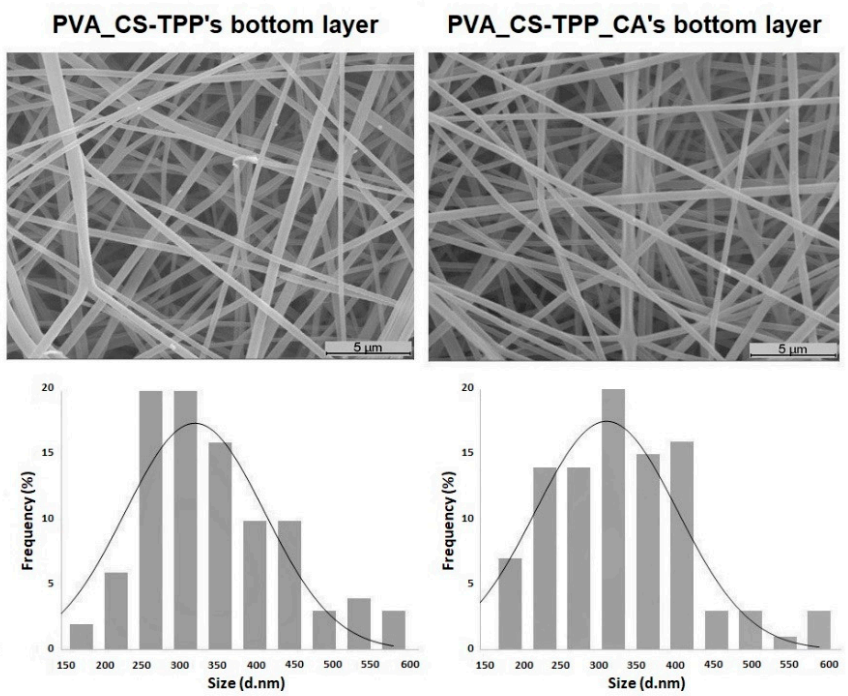

PVA_CS-TPP_CA's bottom layer

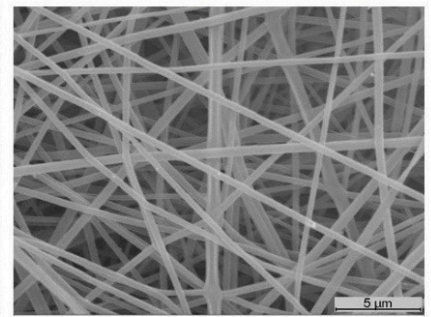

Cross-section
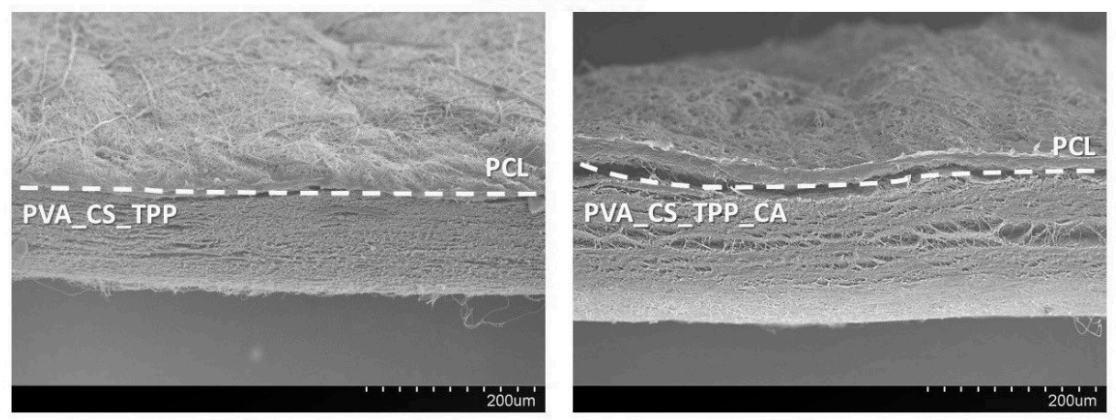

Figure 1. Morphology and fiber diameter distribution of the Polycaprolactone (PCL)'s top layer and the Poly(vinyl alcohol) (PVA) and Chitosan-Sodium tripolyphosphate (CS-TPP) (PVA_CS-TPP) and PVA_CS-TPP containing Centella asiatica (L.) (CA)'s bottom layers (a); and cross-sectional SEM images of the double-layered membranes; (b) PCL/PVA_CS-TPP with crude CA extract (on the right) and without (on the left). 
According to the cross-sectional image, Figure $1 \mathrm{~b}$, it is possible to observe the two different layers of the produced double-layered nanocomposites membranes.

\subsubsection{Attenuated Total Reflectance-Fourier Transform Infrared Spectroscopy Study}

The acquired ATR-FTIR spectra of the produced double-layered nanocomposites membranes are presented in Figure 2. The spectrum of the PCL's top layer displays its characteristic bands, Figure 2a. The peaks at 2865.22 and $2943.10 \mathrm{~cm}^{-1}$ belongs to the symmetric and asymmetric $\mathrm{CH}_{2}$ stretching vibration, while the band at $1722.95 \mathrm{~cm}^{-1}$ corresponds to the $\mathrm{C}=\mathrm{O}$ stretching vibration [47].

a

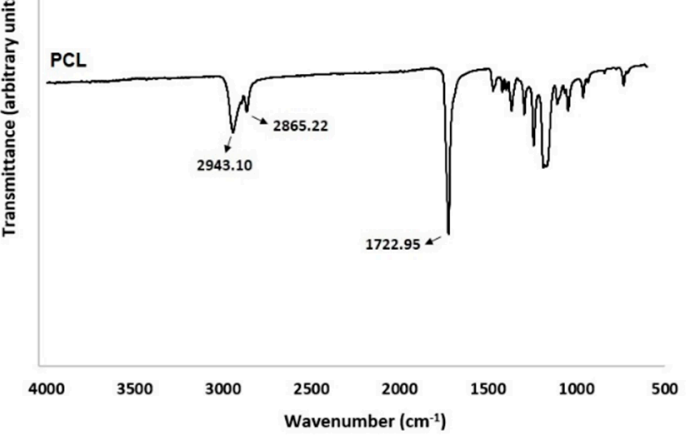

b

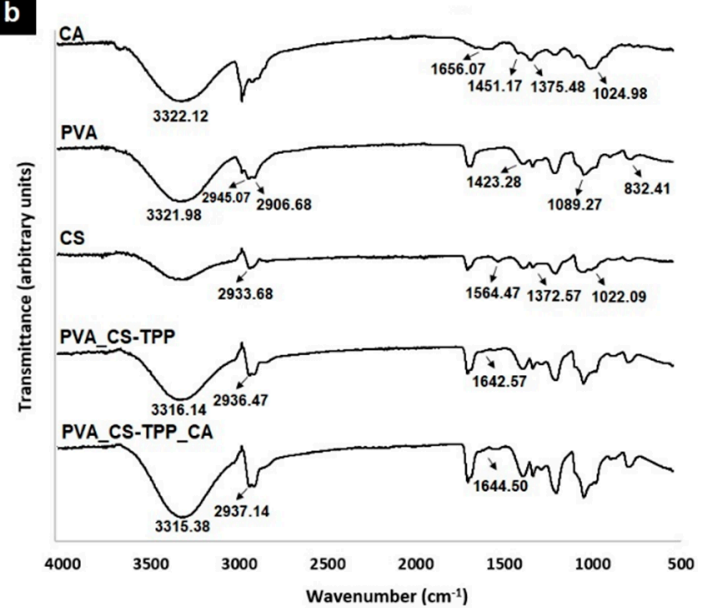

Figure 2. ATR-FTIR analysis of the produced double-layered membranes. FTIR spectra of the PCL's top layer (a), the bottom layers of PVA_CS-TPP and PVA_CS-TPP_CA, and their raw materials (b).

In turn, the spectrum of the PVA_CS-TPP's bottom layer shows the characteristic peaks of the PVA and $\mathrm{CS}$ at 3316.14 and $2936.47 \mathrm{~cm}^{-1}$, attributed to the $\mathrm{O}-\mathrm{H}$ and $\mathrm{CH}_{2}$ stretching vibration, respectively, and a peak at $1642.57 \mathrm{~cm}^{-1}$ assigned to $\mathrm{C}=\mathrm{O}$ stretching of a primary amide, Figure $2 \mathrm{~b}$. These bands revealed that the PVA and CS-TPP were successfully dispersed in the nanofibers [31]. Moreover, when the CA extract was incorporated into the PVA_CS-TPP nanofibers, a higher intensity of the peaks was observed once the characteristic peaks of the crude CA extract overlapped with the bands of PVA_CS-TPP, Figure 2b. A similar effect was previously reported by Amina et al. [48], who showed that the characteristic peaks of PU nanofibers overlapped with the bands of aqueous extract of Grewia mollis (G. mollis), leading to a higher intensity in the PU/G. mollis nanofibers' spectrum. However, the spectrum of raw CA confirms its characteristics peaks at $3322.12 \mathrm{~cm}^{-1}(\mathrm{O}-\mathrm{H}$ stretching vibration of carboxylic acid group), $1656.07 \mathrm{~cm}^{-1}$ (C-O stretching vibration), $1451.17 \mathrm{~cm}^{-1}$ (C-H in-plane bending vibration), $1375.48 \mathrm{~cm}^{-1}$ (C-N stretching vibration, aromatic amide), and $1024.98 \mathrm{~cm}^{-1}$ (C-O stretching) [49].

\subsubsection{Differential Scanning Calorimetry (DSC)}

The thermal properties of both layers (PCL's top layer and the bottom layers of PVA_CS-TPP and PVA_CS-TPP containing crude CA extract) were evaluated by DSC, as demonstrated in Figure 3.

In PCL's top layer, the endothermic peak at $62.96{ }^{\circ} \mathrm{C}$ corresponds to the melting temperature $\left(\mathrm{T}_{\mathrm{m}}\right)$ of PCL. This result is in agreement with the data available in the literature for electrospun PCL membranes $\left(\mathrm{T}_{\mathrm{m}}(\mathrm{PCL})=60.10^{\circ} \mathrm{C}\right)[50]$.

On the other hand, the raw PVA_CS with the PVA_CS-TPP nanofibers display an endothermic peak at $62.24^{\circ} \mathrm{C}$ corresponding to the evaporation of water and acetic acid solvents [51,52]. In addition, a weak endothermic peak was found at $188.43{ }^{\circ} \mathrm{C}$, which is due to the melting of PVA crystals [51]. Additionally, the DSC thermograms suggest that the presence of CS-TPP shifted the endothermic peaks to a higher temperature, confirming the thermal stability of the ionically cross-linked electrospun 
PVA_CS-TPP nanofibers. Moreover, the incorporation of the crude CA extract slightly changed the $\mathrm{T}_{\mathrm{m}}$ of the PVA_CS-TPP nanofibers, indicating that the incorporation of the crude plant extract slightly enhance the thermal properties of the bottom layer of the produced double-layered nanocomposite membrane. Therefore, the electrospun PVA_CS-TPP_CA nanofibers were revealed to be thermally stable to support cell growth, which is essential for improving the healing process.

a

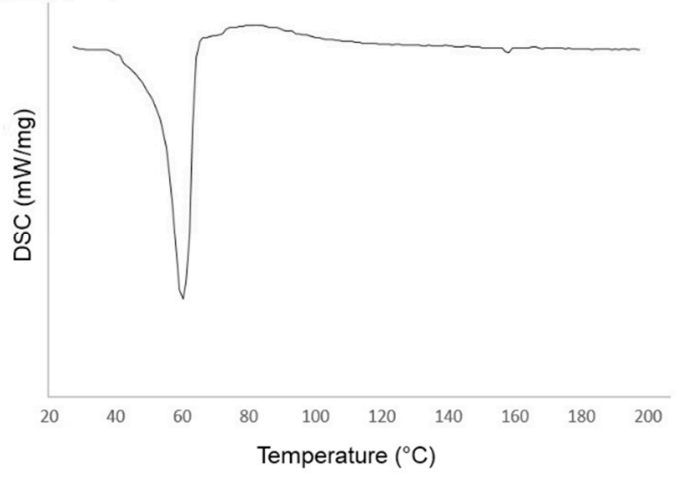

$-\mathrm{PCL}$

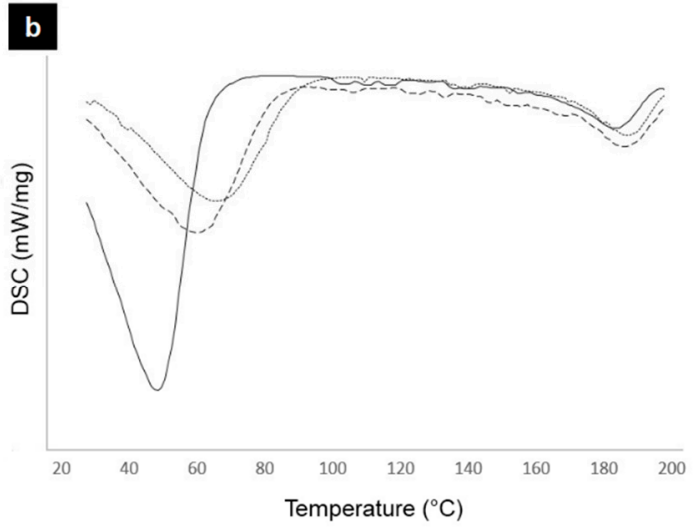

- PVA_CS ----- PVA_CS-TPP ……PVA_CS-TPP_CA

Figure 3. Characterization of the thermal behavior of the produced double-layered membranes. DSC curves of the PCL's top layer (a); and the bottom layers of PVA_CS, PVA_CS-TPP, and PVA_CS-TPP_CA (b).

Similarly, Ghaseminezhad et al. [53] developed electrospun PCL/Gelatin nanofibers loaded with different amounts of Althea officinalis (AO) and demonstrated that till $15 \mathrm{wt} \%$ AO the thermal stability of these electrospun nanofibers was slightly improved.

3.2.4. Assessment of the Mechanical Characteristics of the Produced Electrospun Double-Layered Nanocomposites Membranes

The mechanical characteristics, like tension, elasticity, and Young's modulus, of the produced double-layered nanocomposites membranes, are summarized in Table 1. The electrospun PCL/PVA_CS-TPP membrane exhibited a tensile strength of $3.96 \pm 0.99 \mathrm{MPa}$, Young's modulus of $38.16 \pm 5.32 \mathrm{MPa}$, and an elongation at break of $10.39 \pm 1.89 \%$. However, the mechanical strength of the nanocomposites membranes was decreased after incorporation of the crude CA extract. The tensile strength and Young's modulus of the PCL/PVA_CS-TPP_CA were reduced to $3.03 \pm 0.67 \mathrm{MPa}$ and $36.36 \pm 7.29 \mathrm{MPa}$, respectively. The crude CA extract also had a slight effect on the elongation at break $(8.31 \pm 0.61 \%)$. Nevertheless, the obtained values are close to those exhibited by native human skin, Table 1 .

Table 1. Evaluation of the mechanical properties of the produced Polycaprolactone (PCL)/ Poly(vinyl alcohol) (PVA) and Chitosan-Sodium tripolyphosphate (CS-TPP) (PVA_CS-TPP) nanofibrous membranes with and without crude Centella asiatica (L.) (CA) extract and comparison with the native human skin values.

\begin{tabular}{ccccc}
\hline & Tensile Strength (MPa) & Young's Modulus (MPa) & Elongation at Break (\%) & Thickness (mm) \\
\hline PCL/PVA_CS-TPP & $3.96 \pm 0.99$ & $38.16 \pm 5.32$ & $10.39 \pm 1.89$ & $0.12 \pm 0.01$ \\
\hline PCL/PVA_CS-TPP_CA & $3.03 \pm 0.67$ & $36.36 \pm 7.29$ & $8.31 \pm 0.61$ & $0.10 \pm 0.02$ \\
\hline Native skin & $2.50-30.00^{\text {a }}$ & $0.40-20.00^{\text {a }}$ & $10.00-115.00^{\text {a }}$ & - \\
\hline \multicolumn{5}{c}{${ }^{a}$ Native skin values were obtained from reference [10]. }
\end{tabular}

According to what was described above, several studies have shown that the incorporation of the crude plant extracts into electrospun nanofibers decreases the mechanical strength of the membranes, due to its weaker mechanical properties [11,54]. In turn, synthetic polymers like PCL have exhibited excellent mechanical performance [55]. 
Thereby, the two layers of the double-layered nanocomposites membranes attached will provide good resilience and compliance to cover a wound area, resulting in effective wound healing with minimal scarring.

\subsubsection{Measurement of the Total Porosity}

The wound dressings' porosity is a very important parameter for an effective healing process to occur. Herein, the porosity of the PCL's top layer was found to be $64.01 \pm 10.61 \%$, Figure 4a. This value is in accordance with other studies that used the lowest porosity of the PCL as a protective layer against bacteria penetration $[11,56]$. On the other hand, the bottom layers of the PVA_CS-TPP and PVA_CS-TPP_CA displayed porosities of $92.92 \pm 1.16 \%$ and $96.88 \pm 1.14 \%$, respectively, Figure 4 a. The data obtained reveal that the porosity values of the bottom layers, which play a vital role in the healing process, are in the preferred range of 60 to $90 \%$ for cell adhesion, migration, and proliferation. In addition, a highly porous structure is beneficial for the improvement of the production of the new ECM components [7].

\section{a}

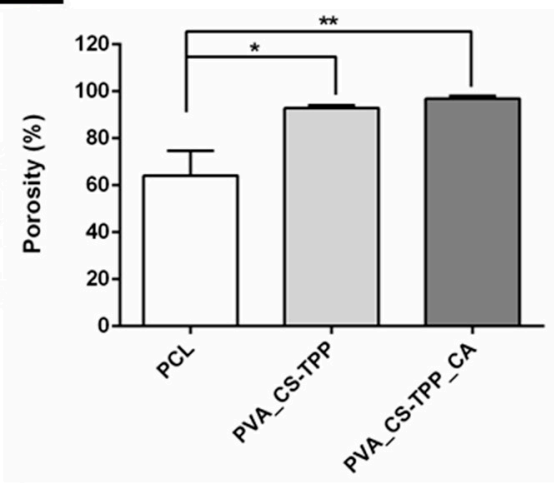

c

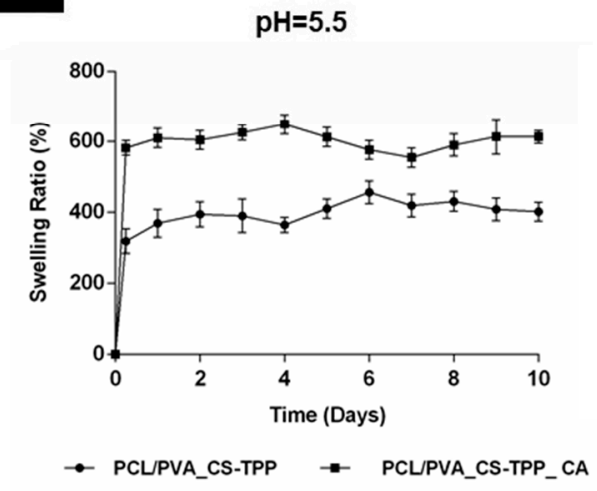

\section{b}

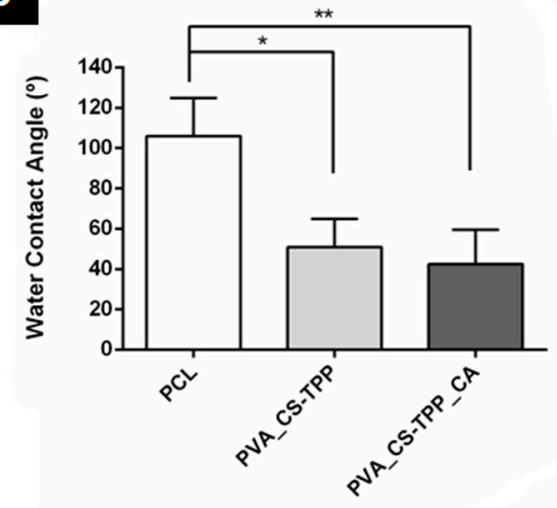

d

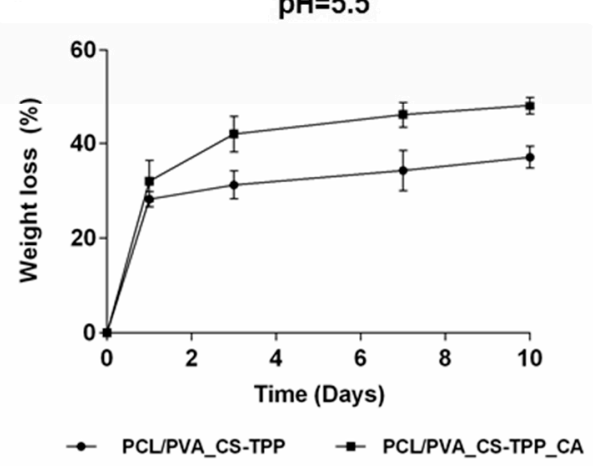

Figure 4. Characterization of the total porosity (a); wettability (b); swelling profile (c); and weight loss at $\mathrm{pH}=5.5(\mathbf{d})$ of the produced double-layered membranes. (Data are represented as average \pm standard deviation (S.D.), ${ }^{*} p<0.05$ and $\left.{ }^{* *} p<0.001\right)$.

\subsubsection{Evaluation of Wettability Properties}

The wettability of the wound dressing materials is a crucial parameter that affects their biological performance [57]. Herein, the surface wettability of both layers of the produced double-layered nanocomposite membranes was investigated from the WCA between the surface material and water droplets using the sessile drop technique. The PCL's top layer of nanocomposites membranes exhibited a WCA value of $105.93 \pm 18.85^{\circ}$, confirming its hydrophobic character conferred by PCL aliphatic chains, Figure 4b. On the other hand, the bottom layers of the PVA_CS-TPP, which is in contact with the 
wound, showed a WCA value of $50.83 \pm 13.97^{\circ}$. This value decreased to $42.50 \pm 16.93^{\circ}$ when the crude CA extract was incorporated in this layer (PVA_CS-TPP_CA), Figure 4b. Such behavior is associated with the hydrophilic character of the plant components. Therefore, the moderate wettability of the PVA_CS-TPP and PVA_CS-TPP_CA nanofibers is in accordance with the literature since WCA values between $40^{\circ}$ and $70^{\circ}$ could lead to better cell adhesion, migration, and proliferation. Furthermore, values within this range are more prone to provide moist environments, enhancing the healing process, than the hydrophobic (WCA $>90^{\circ}$ ) or super hydrophilic $\left(\mathrm{WCA}<20^{\circ}\right.$ ) surfaces, as previously mentioned in the literature $[56,57]$.

\subsubsection{Analysis of the In Vitro Swelling Behavior}

The water absorption capability of the produced electrospun double-layered nanocomposites membranes plays an important role in the absorption of wound exudates providing a moist wound environment [58]. The swelling behavior might contribute to avoiding an extreme level of the moisture at the wound surface, and the dryness of the wound, which can lead to a delay in healing [58].

The swelling profiles of the PCL/PVA_CS-TPP and PCL/PVA_CS-TPP_CA membranes were evaluated after immersion in $\mathrm{PBS}$ at $\mathrm{pH}=5.5$ for 10 days to simulate the acidic environment at the wound site, Figure 4c. The electrospun PCL/PVA_CS-TPP membrane containing crude CA extract displayed a higher water absorption capability $(\sim 600 \%)$ than the PCL/PVA_CS-TPP membrane $(\sim 400 \%)$. Thus, the results suggest that the incorporation of CA extract in the bottom layer of PVA_CS-TPP provided hydrophilicity to the polymer blend, contributing to a higher amount of water retained in the interconnected fibrous pores and increasing the water absorption ratio. A similar effect was previously described by Yousefi et al. [35], who found a higher water-uptake ability when Henna extracts were incorporated into CS/Poly(ethylene oxide) (PEO) nanofibrous mats. Regarding that, the CS/PEO/Henna extract nanofibrous mats were demonstrated to exhibit the capability to efficiently remove the exudate from the wound, adjusting the wound moisture.

\subsubsection{Study of the In Vitro Biodegradation Profile}

An ideal wound dressing must display suitable biodegradability and a degradation profile consistent with the wound repair and regeneration [59]. Herein, the electrospun double-layered nanocomposites membranes were fabricated from biodegradable materials, and the percentages of weight loss are presented in Figure 4d. The degradation studies showed that the PCL/PVA_CS-TPP exhibited a weight loss of $37.10 \pm 2.33 \%$, while the PCL/PVA_CS-TPP_CA undergo a weight loss of $48.04 \pm 1.82 \%$, respectively. Therefore, the hydrophilic character of crude CA extract contributed to both increases the water absorption and a slightly faster weight loss of the nanofibers. In addition, the PVA and CS present in the bottom layer are characterized by suffering higher weight losses than the PCL's top layer, which displays a slow in vitro degradation profile [11].

\subsubsection{Water Vapor Transmission Rate (WVTR) Analysis}

The membrane's permeability is another important parameter which can ensure suitable oxygenation of the wound environment and stimulate new blood vessel, sustaining the complex cellular events during the healing process [60]. In addition, the wound dressing membranes should avoid excessive dehydration as well as the build-up of exudates [7]. The data available in the literature demonstrated that the ideal WVTR value for wound dressing materials should be between $2000-2500 \mathrm{~g} / \mathrm{m}^{2} /$ day [7]. Herein, a WVTR of $1162.94 \pm 116.10 \mathrm{~g} / \mathrm{m}^{2} /$ day and $1757.12 \pm 67.69 \mathrm{~g} / \mathrm{m}^{2} /$ day were measured for PCL/PVA_CS-TPP and PCL/PVA_CS-TPP_CA, respectively. These values appeared to be outside the range recommended for an ideal dressing. However, the WVTR values obtained herein are within the range displayed by commercial wound dressings $\left(426-2047 \mathrm{~g} / \mathrm{m}^{2} /\right.$ day) [61]. 


\subsection{Analysis of the In Vitro CA Release from Electrospun Double-Layered Nanocomposites Membranes}

Nowadays, loading bioactive agents into the electrospun nanofibers can be achieved through the simple blending of the polymer solution before spinning, post-spinning surface functionalization methods, or using core-shell electrospinning techniques [7]. The choice of the method is dependent on the intended application and based on the preferred bioactive agent release profile.

Herein, crude CA extract, a medicinal plant, was selected to be incorporated into the PVA_CS-TPP nanofibers to improve the healing properties of the double-layered nanocomposites membranes. The cumulative release profile of the crude CA extract from the bottom's nanofibers is shown in Figure 5. The amount of CA released from the bottom layer reached $84.22 \pm 2.08 \%$ after 10 days. The slower and sustained release of CA could be influenced by the nature of the plant components as well as the pore size of the nanofibers. Further, the swelling ability and consequential diffusion and degradation of the polymers on exposure to the aqueous medium ( $\mathrm{PBS} \mathrm{pH}=5.5$ ) can also affect the release mechanism of the crude CA extract [62,63].

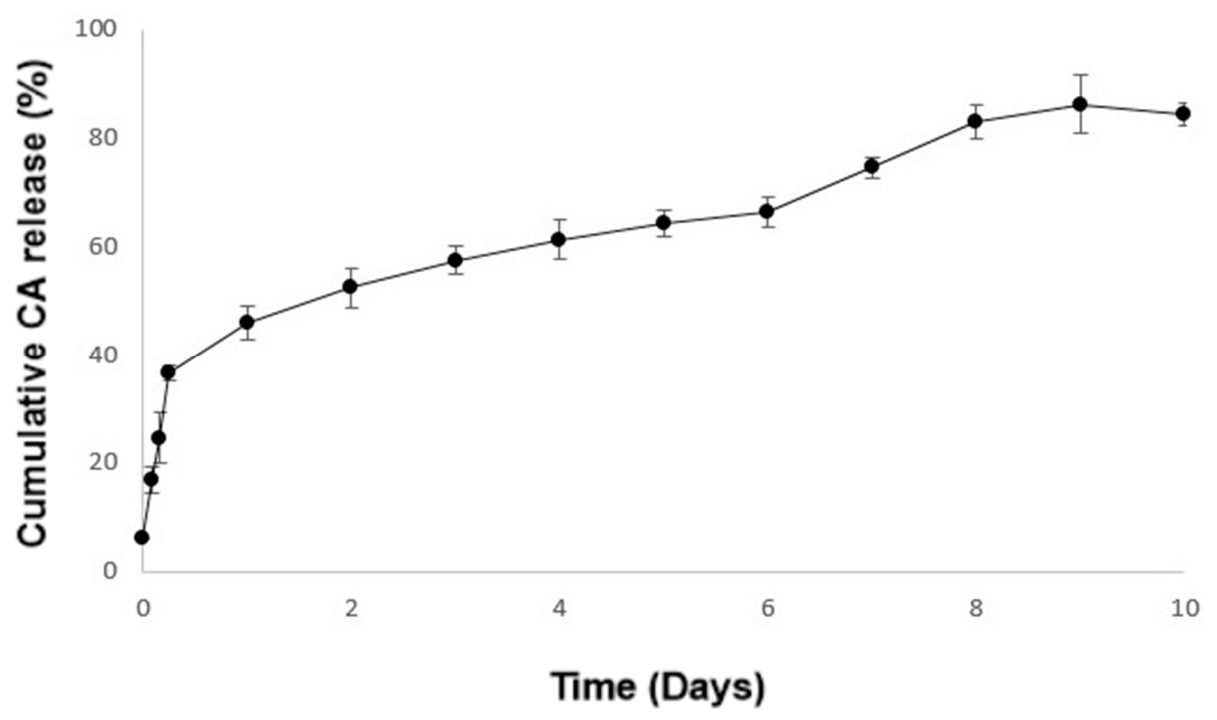

Figure 5. Cumulative release profile of the crude CA extract from the bottom's PVA_CS-TPP nanofibers at $\mathrm{pH}=5.5$.

Regarding all the above-mentioned, the obtained release profile is crucial for the produced bottom layer to prevent wound bacterial colonization and infection.

\subsection{Assessment of the Antibacterial Properties of the Produced Electrospun Double-Layered Nanocomposites Membranes}

Wounded skin is usually associated with a higher level of bacterial colonization and subsequent biofilm formation, which can prolong the inflammatory phase of healing, delay collagen synthesis, and impede re-epithelialization $[1,5,6]$. Although the inflammatory cells inducing phagocytosis of the pathogens, high growth of bacteria at the wound site lead to an extended infiltration of immune cells and increase the production of pro-inflammatory cytokines $[1,5,6]$. Therefore, an ideal wound dressing material should provide an unfavorable environment for bacteria growth or inhibit the infiltration of bacteria at the wound site.

In this study, the behavior of the PCL's top layer was similar to the control group (filter paper with a pore size of $0.22 \mu \mathrm{m}$ ), proving the capability to act as a protective barrier against $S$. aureus and $P$. aeruginosa due to its low porosity, Figure 6 . The antibacterial activity of the bottom layers (PVA_CS-TPP and PVA_CS-TPP_CA) was also evaluated. PVA_CS-TPP showed an inhibitory effect of $61.80 \pm 4.45 \%$ and $48.41 \pm 9.94 \%$ against $S$. aureus and P. aeruginosa, respectively. However, an increased inhibitory effect on bacterial growth, $99.96 \pm 6.04 \%$ and $99.94 \pm 0.67 \%$ for S. aureus and P. aeruginosa, 
was observed when the crude CA extract was incorporated, Figure 6 . This result confirmed that the CA's secondary metabolites, like triterpenoid saponins (asiatic acid, asiaticoside, and madecassoside) exhibit a high ability to inhibit bacterial growth, as previously reported in different research studies [34,64]. Hence, the PVA_CS-TPP layer containing CA extract is essential to provide an aseptic environment at the wound site.

a

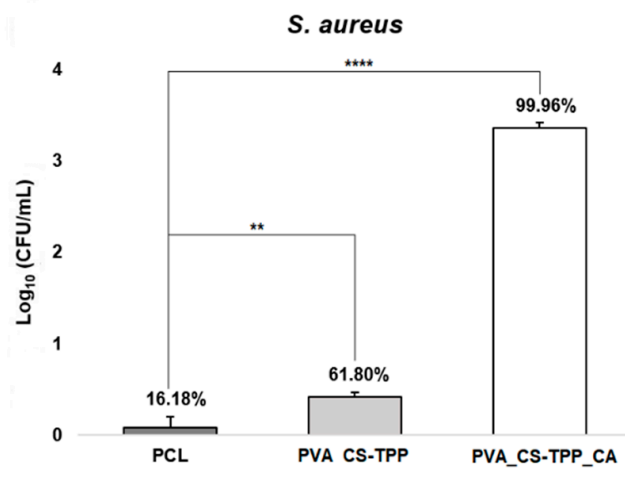

b

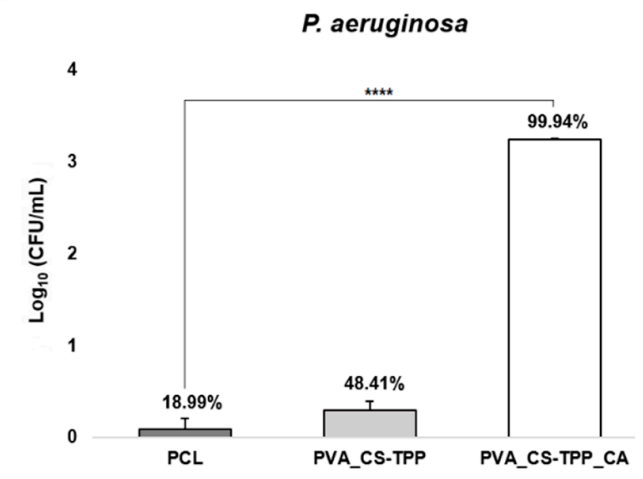

Figure 6. Evaluation of the antibacterial potential of the PCL's top layer and the PVA_CS-TPP_CA and PVA_CS-TPP_CA's bottom layers against Staphylococcus aureus (S. aureus) (a) and Pseudomonas aeruginosa $(P$. aeruginosa $)(\mathbf{b})$. (Data are represented as average \pm standard deviation (S.D.), ${ }^{* *} p<0.001$ and $\left.{ }^{* * * *} p<0.0001\right)$.

\subsection{Analysis of the In Vitro Cell Viability}

In this study, the effect of the produced double-layered nanocomposites membranes on cell viability and proliferation was investigated through MTT assay for 1,3, and 7 days and the results are shown in Figure 7. Overall, it was found that the PCL/PVA_CS-TPP and PCL/PVA_CS-TPP containing CA extract displayed excellent cell viability (over 90\%) when tested on NHDF cells. The non-toxic properties could be attributed to the porous and hydrophilic character exhibited by the bottom layers, which can support cell adhesion and proliferation.

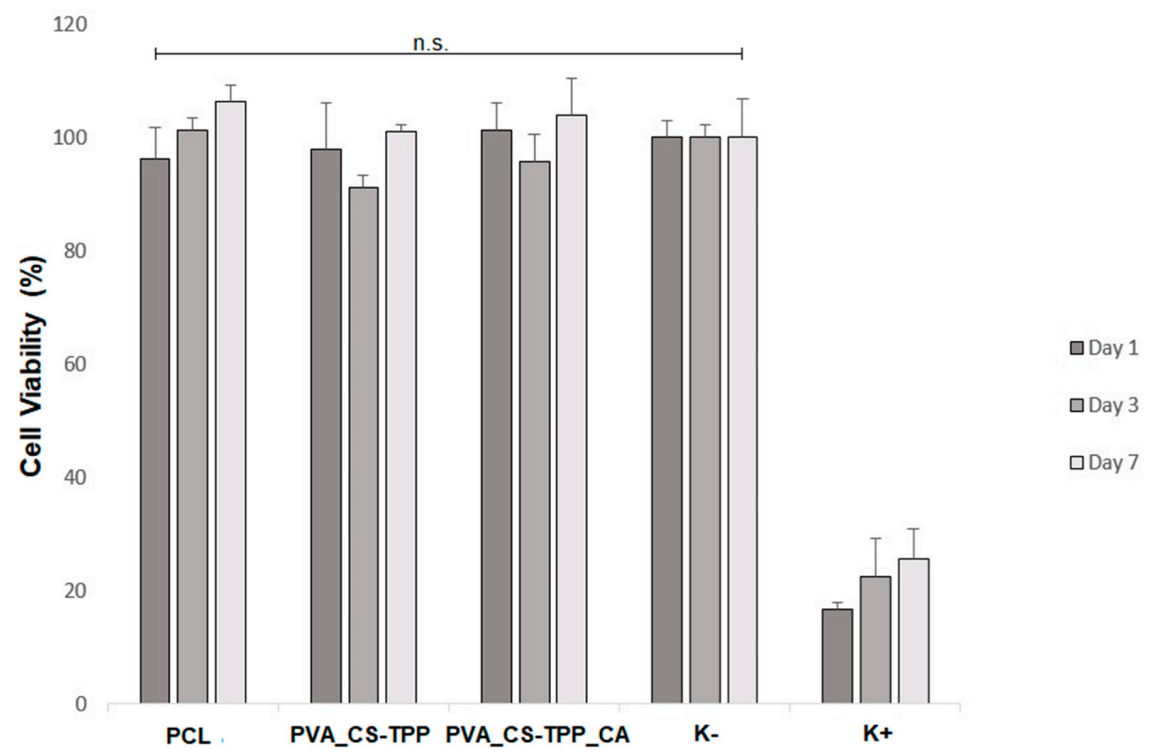

Figure 7. Growth of normal human dermal fibroblasts (NHDF) cells on the PCL's top layer and the PVA_CS-TPP and PVA_CS-TPP_CA's bottom layers detected by 3-(4,5-Dimethyl-2-thiazolyl)-2,5-diphenyl-2H-tetrazolium bromide (MTT) assay in term of cell viability after 1,3 , and 7 days. 
Similarly, Yousefi et al. [35] demonstrated that the incorporation of the Henna extracts into CS/PEO nanofibrous mats did not affect the proliferation and viability of the NHF cells, confirming that they lack cytotoxic effects.

\section{Conclusions}

In the present study, the electrospun double-layered nanocomposite membrane of PCL, PVA, and CS-TPP was incorporated with crude CA extract to improve skin regeneration. The obtained nanocomposite material was characterized in terms of physical, chemical, and biological features to verify its suitability to be applied as an advanced wound dressing. The results showed that the PCL's layer could act as a protective barrier against external contaminants, and simultaneously, the PVA_CS-TPP_CA's bottom layer was revealed to be effective in exudate absorption and providing a moist environment. Moreover, PVA_CS-TPP_CA improved the antibacterial activity of the double-layered nanocomposite membrane against $S$. aureus and P. aeruginosa, which is advantageous to prevent microbial penetration. This novel nano-carrier was also able to achieve a controlled release of CA and closely resemble the mechanical properties of native skin.

Furthermore, the produced double-layered nanocomposites membranes did not provide a cytotoxic effect on NHDF cell culture. Hence, these findings emphasize the potential to blend PCL and PVA_CS-TPP nanofibers with the beneficial properties of crude CA extract for wound healing applications.

Shortly, other potential healing benefits of these double-layered nanocomposites membranes will be further tested, as well as their efficacy in animal models to establish in vivo data.

Author Contributions: C.M. performed the investigation and wrote the paper; R.F. supervised the paper; I.C.G. supervised and validated the data of the paper. All authors have read and agreed to the published version of the manuscript.

Funding: The authors are grateful for the support given by the FibEnTech Research Unit (Project UIDB/00195/2020). Cláudia Mouro also acknowledges a PhD fellowship from the Foundation for Science and Technology (FCT) (PD/BD/113550/2015).

Acknowledgments: The authors would like to thank Ana Raquel Nunes for her help in the cytotoxic assay and Eng. Ana Paula Gomes for her help in SEM and DSC analysis.

Conflicts of Interest: The authors declare no conflict of interest, financial or otherwise.

\section{References}

1. Sousa Coelho, D.; Veleirinho, B.; Alberti, T.; Maestri, A.; Yunes, R.; Fernando Dias, P.; Maraschin, M. Electrospinning Technology: Designing Nanofibers toward Wound Healing Application. In Nanomaterials_-Toxicity, Human Health and Environment; IntechOpen: London, UK, 2018; pp. 1-19.

2. Williamson, D.; Harding, K. Wound healing. Medicine 2004, 32, 4-7. [CrossRef]

3. Chouhan, D.; Dey, N.; Bhardwaj, N.; Mandal, B.B. Emerging and innovative approaches for wound healing and skin regeneration: Current status and advances. Biomaterials 2019, 216, 119267. [CrossRef] [PubMed]

4. Mihai, M.M.; Dima, M.B.; Dima, B.; Holban, A.M. Nanomaterials for wound healing and infection control. Materials 2019, 12, 2176. [CrossRef] [PubMed]

5. Sarheed, O.; Ahmed, A.; Shouqair, D.; Boateng, J. Antimicrobial Dressings for Improving Wound Healing. In Wound Healing - New Insights into Ancient Challenges; InTech: London, UK, 2016; pp. 373-398.

6. Paladini, F.; Pollini, M. Antimicrobial Silver Nanoparticles for Wound Healing Application: Progress and Future Trends. Materials 2019, 12, 2540. [CrossRef]

7. Pilehvar-Soltanahmadi, Y.; Dadashpour, M.; Mohajeri, A.; Fattahi, A.; Sheervalilou, R.; Zarghami, N. An Overview on Application of Natural Substances Incorporated with Electrospun Nanofibrous Scaffolds to Development of Innovative Wound Dressings. Mini-Rev. Med. Chem. 2017, 18, 414-427. [CrossRef] [PubMed]

8. Andreu, V.; Mendoza, G.; Arruebo, M.; Irusta, S. Smart dressings based on nanostructured fibers containing natural origin antimicrobial, anti-inflammatory, and regenerative compounds. Materials 2015, 8, 5154-5193. [CrossRef] 
9. Zhang, W.; Ronca, S.; Mele, E. Electrospun nanofibres containing antimicrobial plant extracts. Nanomaterials 2017, 7, 42. [CrossRef]

10. dos Santos, D.M.; Leite, I.S.; de Lacerda Bukzem, A.; de Oliveira Santos, R.P.; Frollini, E.; Inada, N.M.; Campana-Filho, S.P. Nanostructured electrospun nonwovens of poly( $\varepsilon$-caprolactone)/quaternized chitosan for potential biomedical applications. Carbohydr. Polym. 2018, 186, 110-121. [CrossRef]

11. Miguel, S.P.; Ribeiro, M.P.; Coutinho, P.; Correia, I.J. Electrospun polycaprolactone/Aloe Vera_chitosan nanofibrous asymmetric membranes aimed for wound healing applications. Polymers 2017, 9, 183. [CrossRef]

12. Bai, Y.; Wang, D.; Zhang, Z.; Pan, J.; Cui, Z.; Yu, D.-G.; Annie Bligh, S.-W. Testing of fast dissolution of ibuprofen from its electrospun hydrophilic polymer nanocomposites. Polym. Test. 2020, 106872. [CrossRef]

13. Wang, K.; Wang, P.; Wang, M.; Yu, D.G.; Wan, F.; Bligh, S.W.A. Comparative study of electrospun crystal-based and composite-based drug nano depots. Mater. Sci. Eng. C 2020, 113, 110988. [CrossRef] [PubMed]

14. Huang, C.K.; Zhang, K.; Gong, Q.; Yu, D.G.; Wang, J.; Tan, X.; Quan, H. Ethylcellulose-based drug nano depots fabricated using a modified triaxial electrospinning. Int. J. Biol. Macromol. 2020, 152, 68-76. [CrossRef] [PubMed]

15. Kang, S.; Hou, S.; Chen, X.; Yu, D.G.; Wang, L.; Li, X.; Williams, G.R. Energy-saving electrospinning with a concentric teflon-core rod spinneret to create medicated nanofibers. Polymers 2020, 12, 2421. [CrossRef] [PubMed]

16. Liu, Y.; Liu, X.; Liu, P.; Chen, X.; Yu, D.G. Electrospun multiple-chamber nanostructure and its potential self-healing applications. Polymers 2020, 12, 2413. [CrossRef] [PubMed]

17. Wang, M.; Li, D.; Li, J.; Li, S.; Chen, Z.; Yu, D.G.; Liu, Z.; Guo, J.Z. Electrospun Janus zein-PVP nanofibers provide a two-stage controlled release of poorly water-soluble drugs. Mater. Des. 2020, 196, 109075. [CrossRef]

18. Hou, J.; Yang, J.; Zheng, X.; Wang, M.; Liu, Y.; Yu, D.G. A nanofiber-based drug depot with high drug loading for sustained release. Int. J. Pharm. 2020, 583. [CrossRef]

19. Ding, Y.; Dou, C.; Chang, S.; Xie, Z.; Yu, D.G.; Liu, Y.; Shao, J. Core-shell eudragit S100 nanofibers preparedvia triaxial electrospinning to providea colon-targeted extended drug release. Polymers 2020, 12, 2034. [CrossRef]

20. Wang, M.; Hou, J.; Yu, D.G.; Li, S.; Zhu, J.; Chen, Z. Electrospun tri-layer nanodepots for sustained release of acyclovir. J. Alloys Compd. 2020, 846, 156471. [CrossRef]

21. Chang, S.; Wang, M.; Zhang, F.; Liu, Y.; Liu, X.; Yu, D.G.; Shen, H. Sheath-separate-core nanocomposites fabricated using a trifluid electrospinning. Mater. Des. 2020, 192, 108782. [CrossRef]

22. Hassanin, A.; El-Moneim, A.A.; Ghaniem, M.; Nageh, H. Nanocomposite multilayer fibrous membrane for sustained drug release. In Advanced Materials Research; Trans Tech Publications Ltd.: Zurich, Switzerland, 2014; Volume 894, pp. 364-368.

23. Rezk, A.I.; Lee, J.Y.; Son, B.C.; Park, C.H.; Kim, C.S. Bi-layered nanofibers membrane loaded with titanium oxide and tetracycline as controlled drug delivery system for wound dressing applications. Polymers 2019, 11, 1602. [CrossRef]

24. López-Calderón, H.D.; Avilés-Arnaut, H.; Galán-Wong, L.J.; Almaguer-Cantú, V.; Laguna-Camacho, J.R.; Calderón-Ramón, C.; Escalante-Martínez, J.E.; Arévalo-Niño, K. Electrospun Polyvinylpyrrolidone-Gelatin and Cellulose Acetate Bi-Layer Scaffold Loaded with Gentamicin as Possible Wound Dressing. Polymers 2020, 12, 2311. [CrossRef] [PubMed]

25. Bhullar, S.K.; Buttar, H.S. Perspectives on nanofiber dressings for the localized delivery of botanical remedies in wound healing. AIMS Mater. Sci. 2017, 4, 370-382. [CrossRef]

26. Hajialyani, M.; Tewari, D.; Sobarzo-Sánchez, E.; Nabavi, S.M.; Farzaei, M.H.; Abdollahi, M. Natural product-based nanomedicines for wound healing purposes: Therapeutic targets and drug delivery systems. Int. J. Nanomed. 2018, 13, 5023-5043. [CrossRef] [PubMed]

27. Cheesman, M.J.; Ilanko, A.; Blonk, B.; Cock, I.E. Developing new antimicrobial therapies: Are synergistic combinations of plant extracts/compounds with conventional antibiotics the solution? Pharmacogn. Rev. 2017, 11, 57-72. [CrossRef] [PubMed]

28. Pedram Rad, Z.; Mokhtari, J.; Abbasi, M. Fabrication and characterization of PCL/zein/gum arabic electrospun nanocomposite scaffold for skin tissue engineering. Mater. Sci. Eng. C 2018, 93, 356-366. [CrossRef]

29. Suryamathi, M.; Ruba, C.; Viswanathamurthi, P.; Balasubramanian, V.; Perumal, P. Tridax Procumbens Extract Loaded Electrospun PCL Nanofibers: A Novel Wound Dressing Material. Macromol. Res. 2019, 27, 55-60. [CrossRef] 
30. Foong, C.Y.; Sultana, N. Fabrication of layer-by-layer electrospun composite membranes based on polylactic acid (PLA) and poly (caprolactone) (PCL)/Chitosan. ARPN J. Eng. Appl. Sci. 2015, 10, 9408-9413.

31. Charernsriwilaiwat, N.; Rojanarata, T.; Ngawhirunpat, T.; Opanasopit, P. Preparation of chitosan-thiamine pyrophosphate/polyvinyl alcohol blend electrospun nanofibers. In Advanced Materials Research; Trans Tech Publications Ltd.: Zurich, Switzerland, 2012; Volume 506, pp. 118-121.

32. Somboonwong, J.; Kankaisre, M.; Tantisira, B.; Tantisira, M.H. Wound healing activities of different extracts of Centella asiatica in incision and burn wound models: An experimental animal study. BMC Complement. Altern. Med. 2012, 12, 103. [CrossRef]

33. Roy, A.; Krishnan, L.; Bharadvaja, N. Qualitative and Quantitative Phytochemical Analysis of Centella asiatica. Nat. Prod. Chem. Res. 2018, 6, 1000323. [CrossRef]

34. Sikareepaisan, P.; Suksamrarn, A.; Supaphol, P. Electrospun gelatin fiber mats containing a herbal-Centella asiatica-Extract and release characteristic of asiaticoside. Nanotechnology 2008, 19, 015102. [CrossRef]

35. Yousefi, I.; Pakravan, M.; Rahimi, H.; Bahador, A.; Farshadzadeh, Z.; Haririan, I. An investigation of electrospun Henna leaves extract-loaded chitosan based nanofibrous mats for skin tissue engineering. Mater. Sci. Eng. C 2017, 75, 433-444. [CrossRef] [PubMed]

36. Alavarse, A.C.; de Oliveira Silva, F.W.; Colque, J.T.; da Silva, V.M.; Prieto, T.; Venancio, E.C.; Bonvent, J.J. Tetracycline hydrochloride-loaded electrospun nanofibers mats based on PVA and chitosan for wound dressing. Mater. Sci. Eng. C 2017, 77, 271-281. [CrossRef] [PubMed]

37. Qasim, S.B.; Zafar, M.S.; Najeeb, S.; Khurshid, Z.; Shah, A.H.; Husain, S.; Rehman, I.U. Electrospinning of chitosan-based solutions for tissue engineering and regenerative medicine. Int. J. Mol. Sci. 2018, 19, 407. [CrossRef] [PubMed]

38. Abbaspour, M.; Makhmalzadeh, B.S.; Rezaee, B.; Shoja, S.; Ahangari, Z. Evaluation of the antimicrobial effect of chitosan/polyvinyl alcohol electrospun nanofibers containing mafenide acetate. Jundishapur J. Microbiol. 2015, 8, e24239. [CrossRef]

39. Sarkar, S.D.; Farrugia, B.L.; Dargaville, T.R.; Dhara, S. Physico-chemical/biological properties of tripolyphosphate cross-linked chitosan based nanofibers. Mater. Sci. Eng. C 2013, 33, 1446-1454. [CrossRef]

40. Nguyen, T.V.; Nguyen, T.T.H.; Wang, S.L.; Vo, T.P.K.; Nguyen, A.D. Preparation of chitosan nanoparticles by TPP ionic gelation combined with spray drying, and the antibacterial activity of chitosan nanoparticles and a chitosan nanoparticle-amoxicillin complex. Res. Chem. Intermed. 2017, 43, 3527-3537. [CrossRef]

41. Yeh, C.C.; Li, Y.T.; Chiang, P.H.; Huang, C.H.; Wang, Y.; Chang, H.I. Characterizing microporous PCL matrices for application of tissue engineering. J. Med. Biol. Eng. 2009, 29, 92-97.

42. Kaur, I.; Suthar, N.; Kaur, J.; Bansal, Y.; Bansal, G. Accelerated Stability Studies on Dried Extracts of Centella asiatica Through Chemical, HPLC, HPTLC, and Biological Activity Analyses. J. Evid.-Based Complement. Altern. Med. 2016, 21, NP127-NP137. [CrossRef]

43. Yao, C.H.; Yeh, J.Y.; Chen, Y.S.; Li, M.H.; Huang, C.H. Wound-healing effect of electrospun gelatin nanofibres containing Centella asiatica extract in a rat model. J. Tissue Eng. Regen. Med. 2015, 11, 905-915. [CrossRef]

44. Pourhojat, F.; Sohrabi, M.; Shariati, S.; Mahdavi, H.; Asadpour, L. Evaluation of poly $\varepsilon$-caprolactone electrospun nanofibers loaded with Hypericum perforatum extract as a wound dressing. Res. Chem. Intermed. 2017, 43, 297-320. [CrossRef]

45. Papenburg, B.J.; Bolhuis-Versteeg, L.A.M.; Grijpma, D.W.; Feijen, J.; Wessling, M.; Stamatialis, D. A facile method to fabricate poly(L-lactide) nano-fibrous morphologies by phase inversion. Acta Biomater. 2010, 6, 2477-2483. [CrossRef]

46. Abrigo, M.; McArthur, S.L.; Kingshott, P. Electrospun nanofibers as dressings for chronic wound care: Advances, challenges, and future prospects. Macromol. Biosci. 2014, 14, 772-792. [CrossRef]

47. Manotham, S.; Pengpat, K.; Eitssayeam, S.; Rujijanagul, G.; Sweatman, D.R.; Tunkasiri, T. Fabrication of Polycaprolactone/Centella asiatica Extract Biopolymer Nanofiber by Electrospinning. Appl. Mech. Mater. 2015, 804, 151-154. [CrossRef]

48. Amina, M.; Al-Youssef, H.M.; Amna, T.; Hassan, S.; El-Shafae, A.M.; Kim, H.Y.; Khil, M.-S. Poly(urethane)/G. Mollis Composite Nanofibers for Biomedical Applications. J. Nanoeng. Nanomanuf. 2012, 2, 85-90. [CrossRef]

49. Rebia, R.A.; Sadon, N.S.B.; Tanaka, T. Natural antibacterial reagents (Centella, propolis, and hinokitiol) loaded into poly[(R)-3-hydroxybutyrate-co-(R)-3-hydroxyhexanoate] composite nanofibers for biomedical applications. Nanomaterials 2019, 9, 1665. [CrossRef] [PubMed] 
50. Hu, J.; Prabhakaran, M.P.; Ding, X.; Ramakrishna, S. Emulsion electrospinning of polycaprolactone: Influence of surfactant type towards the scaffold properties. J. Biomater. Sci. Polym. Ed. 2015, 26, 57-75. [CrossRef] [PubMed]

51. Koosha, M.; Mirzadeh, H.; Shokrgozar, M.A.; Farokhi, M. Nanoclay-reinforced electrospun chitosan/PVA nanocomposite nanofibers for biomedical applications. RSC Adv. 2015, 5, 10479-10487. [CrossRef]

52. Vega-Cázarez, C.A.; López-Cervantes, J.; Sánchez-Machado, D.I.; Madera-Santana, T.J.; Soto-Cota, A.; Ramírez-Wong, B. Preparation and Properties of Chitosan-PVA Fibers Produced by Wet Spinning. J. Polym. Environ. 2018, 26, 946-958. [CrossRef]

53. Ghaseminezhad, K.; Zare, M.; Lashkarara, S.; Yousefzadeh, M.; Aghazadeh Mohandesi, J. Fabrication of althea officinalis loaded electrospun nanofibrous scaffold for potential application of skin tissue engineering. J. Appl. Polym. Sci. 2020, 137, 48587. [CrossRef]

54. Pedram Rad, Z.; Mokhtari, J.; Abbasi, M. Preparation and characterization of Calendula officinalis-loaded PCL/gum arabic nanocomposite scaffolds for wound healing applications. Iran. Polym. J. 2019, 28, 51-63. [CrossRef]

55. Motealleh, B.; Zahedi, P.; Rezaeian, I.; Moghimi, M.; Abdolghaffari, A.H.; Zarandi, M.A. Morphology, drug release, antibacterial, cell proliferation, and histology studies of chamomile-loaded wound dressing mats based on electrospun nanofibrous poly( $\varepsilon$-caprolactone)/polystyrene blends. J. Biomed. Mater. Res. Part B Appl. Biomater. 2014, 102, 977-987. [CrossRef] [PubMed]

56. Trinca, R.B.; Westin, C.B.; da Silva, J.A.F.; Moraes, Â.M. Electrospun multilayer chitosan scaffolds as potential wound dressings for skin lesions. Eur. Polym. J. 2017, 88, 161-170. [CrossRef]

57. Wang, J.; Planz, V.; Vukosavljevic, B.; Windbergs, M. Multifunctional electrospun nanofibers for wound application-Novel insights into the control of drug release and antimicrobial activity. Eur. J. Pharm. Biopharm. 2018, 129, 175-183. [CrossRef] [PubMed]

58. Khoshnevisan, K.; Maleki, H.; Samadian, H.; Doostan, M.; Khorramizadeh, M.R. Antibacterial and antioxidant assessment of cellulose acetate/polycaprolactone nanofibrous mats impregnated with propolis. Int. J. Biol. Macromol. 2019, 140, 1260-1268. [CrossRef]

59. Salvatore, L.; Carofiglio, V.E.; Stufano, P.; Bonfrate, V.; Calò, E.; Scarlino, S.; Nitti, P.; Centrone, D.; Cascione, M.; Leporatti, S.; et al. Potential of electrospun poly(3-hydroxybutyrate)/collagen blends for tissue engineering applications. J. Healthc. Eng. 2018, 2018, 6573947. [CrossRef]

60. Eğri, Ö.; Erdemir, N. Production of Hypericum perforatum oil-loaded membranes for wound dressing material and in vitro tests. Artif. Cells Nanomed. Biotechnol. 2019, 47, 1404-1415. [CrossRef]

61. Garcia-Orue, I.; Santos-Vizcaino, E.; Etxabide, A.; Uranga, J.; Bayat, A.; Guerrero, P.; Igartua, M.; de la Caba, K.; Hernandez, R.M. Development of bioinspired gelatin and gelatin/chitosan bilayer hydrofilms for wound healing. Pharmaceutics 2019, 11, 314. [CrossRef]

62. Goh, Y.-F.; Shakir, I.; Hussain, R. Electrospun fibers for tissue engineering, drug delivery, and wound dressing. J. Mater. Sci. 2013, 48, 3027-3054. [CrossRef]

63. Avci, H.; Ghorbanpoor, H.; Nurbas, M. Preparation of origanum minutiflorum oil-loaded core-shell structured chitosan nanofibers with tunable properties. Polym. Bull. 2018, 75, 4129-4144. [CrossRef]

64. Hou, Q.; Li, M.; Lu, Y.H.; Liu, D.H.; Li, C.C. Burn wound healing properties of asiaticoside and madecassoside. Exp. Ther. Med. 2016, 12, 1269-1274. [CrossRef]

Publisher's Note: MDPI stays neutral with regard to jurisdictional claims in published maps and institutional affiliations.

(C) 2020 by the authors. Licensee MDPI, Basel, Switzerland. This article is an open access article distributed under the terms and conditions of the Creative Commons Attribution (CC BY) license (http://creativecommons.org/licenses/by/4.0/). 